\title{
Variation in Branching Pattern of Splenic Artery- A Cadaveric Study
}

\author{
T Sadeesh $\odot$, G Prabavathy ${ }^{\odot}$ \\ Associate Professor, Department of Anatomy, Mahatma Gandhi Medical College and Research Institute, Pillayarkuppam, Pondicherry, India.
}

\section{Abstract}

Background: Splenic artery is the largest branch of the celiac trunk in adults and is the second-largest next to the common hepatic artery in fetal life. The present study was conducted to assess variation in the branching pattern of the splenic artery. Subjects and Methods: The present cadaveric study was conducted on 54 cadavers embalmed with $10 \%$ formalin. The peritoneal cavity was opened and explored. The celiac trunk, splenic artery and its branches were noted and photographed. Results: out of 54 cadavers, 26 were males and 28 were males. The origin of the splenic artery was from the celiac trunk in 47, a superior mesenteric artery in 4 and abdominal aorta in 3 cases. The difference was significant $(\mathrm{P}<0.05)$. Conclusion: Authors found that surgeons should have a thorough knowledge regarding the branching pattern of the splenic artery. There was variation in the origin of the splenic artery such as from celiac trunk, superior mesenteric artery and abdominal aorta.

Keywords: Splenic artery, Superior mesenteric artery, Abdominal aorta.

Corresponding Author: G Prabavathy, Associate Professor, Department of Anatomy, Mahatma Gandhi Medical College and Research Institute, Pillayarkuppam, Pondicherry, India.

E-mail: prabajai1986@yahoo.com

Received: 17 September 2020

Revised: 26 October 2020

Accepted: 09 November 2020

Published: 22 December 2020

\section{Introduction}

The splenic artery is the largest branch of the celiac trunk in adults and is the second-largest next to the common hepatic artery in fetal life. ${ }^{[1]}$ It is tortuous in its course. It gives branches that supplies to the stomach, pancreas, and greater omentum and ends by supplying the spleen via its terminal branches Incidence of splenic injury is on the rise owing to an increase in accidents. ${ }^{[2]}$

The splenic artery is the largest branch of the celiac trunk. Its origin is at the level of $\mathrm{T} 12 / \mathrm{L} 1$ vertebral bodies. Branches of the splenic artery usually arise at right angles from the stem. The splenic artery divides into constant and inconstant branches. ${ }^{[3]}$ The more constant branches of splenic artery are: Short gastric arteries (vasabrevia), Left gastroepiploic artery, Pancreatic branches, Superior terminal branch (ramuslienogastricus), Inferior terminal branch (ramus lienogastroepiploicus) and Inconstant branches are posterior gastric artery, superior polar artery, inferior polar artery, middle terminal branch. Accessory left gastric artery can be distributed as the anterior cardio-esophageal or posterior cardio-esophageal artery. ${ }^{[4]}$

This variation in the branching pattern of the splenic artery can be correlated with its embryological development. The coeliac, superior mesenteric and inferior mesenteric arteries are derived from the fusion of the vitelline arteries supplying the yolk sac and are located in the dorsal mesentery of the gut. These vessels supply the derivatives of the foregut, midgut and hindgut. Embryologically, the splenic artery is derived from the celiac trunk. It supplies the spleen, pancreas, stomach and greater omentum. The present study was conducted to assess variation in the branching pattern of the splenic artery.

\section{Subjects and Methods}

The present cadaveric study was conducted in the department of Anatomy. It is comprised of 54 cadavers embalmed with $10 \%$ formalin. Ethical approval for the study was obtained before starting the study.

The peritoneal cavity was opened and explored. My stomach was turned superiorly. As the pancreas was uncovered the celiac trunk was identified and the dense autonomic plexus around it was cleared. Then the splenic artery was traced proximally up to its origin and also distally noting its course in relation to the pancreas. The celiac trunk, splenic artery and its branches were noted and photographed. When all the branches and course of the splenic artery were visible, data were noted down. Results were statistically analysed. A P-value of less than 0.05 was considered significant. 


\section{Results}

\begin{tabular}{|lll|}
\hline Table 1: Gender wise distribution & \\
\hline Total- $\mathbf{5 4}$ & & \\
\hline Gender & Male & Female \\
\hline Number & 26 & 28 \\
\hline
\end{tabular}

[Table 1] shows that out of 54 cadavers, 26 were males and 28 were males.

Table 2: Variation in the site of origin of splenic artery

\begin{tabular}{llc}
\hline Origin & Number & P-value \\
Celiac trunk & 47 & 0.001 \\
Superior mesenteric artery & 4 & \\
Abdominal aorta & 3 & \\
\hline
\end{tabular}

[Table 2, Figure 1] shows that the origin of the splenic artery was from a celiac trunk in 47, a superior mesenteric artery in 4 and abdominal aorta in 3 cases. The difference was significant $(\mathrm{P}<0.05)$.

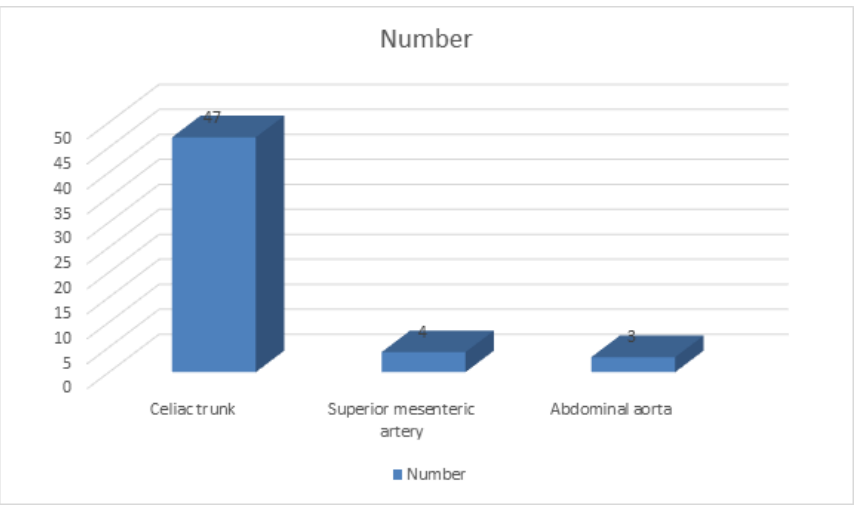

Figure 1: Variation in the site of origin of splenic artery

\section{Discussion}

The vascular architecture of the spleen was presented in detail by Assolent in 1802. Variation of arterial anatomy is very common and occurs in nearly half of the population. The morphologically terminal pattern of the splenic artery is of two types, the Magistral and Distributed. In the Magistral type, lineal branching of the main splenic trunk takes place near the spleen (1-2cm from the hilus). ${ }^{[5]}$ In the Distributed type of splenic artery branching takes place at a distance of 2$12 \mathrm{~cm}$ from the hilum of the spleen. The Splenic artery was previously called a Lineal artery. The splenic artery is one of the branches of the coeliac trunk which in turn arises from the abdominal aorta at the level of the upper border of T12 vertebra $1 .{ }^{[6]}$ In rare instances artery may be doubled, the upper splenic artery being smaller, arises directly from the abdominal aorta and lower from the celiac trunk. The splenic artery is the most common artery to undergo sudden haemodynamic alterations that tend to throw splenic artery tortuous and is the second most common site of intra- abdominal aneurysms. The tortuous course of the splenic artery is considered so variable that no two arteries are alike and may be slightly curved, looped or straight. Ndoye reported that in $66 \%$ of cases, ${ }^{[7]}$ the splenic artery divided as the Distributed type and in $34 \%$ of cases, divided as Magistral type. ${ }^{[7]}$ The present study was conducted to assess variation in the branching pattern of the splenic artery.

In this study, out of 54 cadavers, 26 were males and 28 were males. Jyothi et al, ${ }^{[8]}$ compared the prevalence of variations in the branching pattern of the splenic artery. The variations in the study were almost correlated with the available literature. In some instances, the left gastroepiploic artery, the posterior gastric artery and the accessory left gastric artery took origin from the interior of the spleen so care should be taken during splenectomy. Hence, the arterial blood supply of the spleen is so varied that no two vascular patterns are ever the same.

We found that origin of the splenic artery was from the celiac trunk in 47, a superior mesenteric artery in 4 and an abdominal aorta in 3 cases. Bokan et al, ${ }^{[9]}$ studied the variation in the site of origin of splenic artery in 50 cadavers. It was observed that the splenic artery originated from the celiac trunk in 48 cadavers $(96 \%)$, in 1 cadaver $(02 \%)$ it originated from the abdominal aorta and in 1 cadaver $(02 \%)$ from the superior mesenteric artery. Keeping in mind the clinical importance and to add up more knowledge to the already existing literature.

Shoumara et al, ${ }^{[10]}$ studied the mode of branching of the celiac trunk in 184 Japanese cadavers. They reported 4 cases of the trunk which bifurcated into the left gastric artery and splenic artery. They also observed a case which had a lienomesenteric and gastrohepatic trunk. The splenic artery in this case originated from the lienomesenteric trunk, superior mesenteric artery being its other branch. Oh E et al, ${ }^{[11]}$ in their retrospective review of 159 contrast-enhanced abdominal CT examinations found the incident independent origin of the hepatic and splenic arteries was observedin two of 159 examinations $(1.3 \%)$. This is similar to the report of the angiographic and surgical literature (1\%)

\section{Conclusion}

Authors found that surgeons should have a thorough knowledge regarding the branching pattern of the splenic artery. There was variation in the origin of the splenic artery such as from celiac trunk, superior mesenteric artery and abdominal aorta. 


\section{References}

1. Mikhail Y, Kamd, Nawar R, Rafla. Observation on the mode of termination and parenchymal distribution of splenic artery with evidence of splenic lobation and segmentation. J Anat. 1979; $128: 253-258$.

2. Vandamme JP, Bonte J. The Branches of the Celiac Trunk. Acta Anat. 1985;122(2):110-114. Available from: https://dx. doi.org/10.1159/000145991.

3. Shoumara S, Emura S, Utsumi S, Chen H, Hayakawa D, Yamahira T. Anatomical study of the branches of the celiac trunk. Comparison of the findings with Adachi's classification. Kaibogaku Zasshi. 1991;66:452-461.

4. Oh E, Gross BH, Williams DM, et al. Independent origin of the hepatic and splenic arteries from abdominal aorta: CT demonstration. J Comput Assist Tomogr. 1998;22(4):371377. Available from: https://doi.org/10.1097/00004728199807000-00030.

5. Pandey SK, Bhattacharya S, Mishra RN, Shukla VK. Anatomical variations of the splenic artery and its clinical implications. Clin Anat. 2004;17(6):497-502. Available from: https: //dx.doi.org/10.1002/ca.10220.

6. Petrella S, de Sousa Rodriguez CF, Sgrott EA, Fernandes GJM, Marques SR, Prates JC. Anatomy and Variations of the Celiac Trunk. Int J Morphol. 2007;25(2):249-257. Available from: https://dx.doi.org/10.4067/s0717-95022007000200002.

7. Ndoye JM, Savadogo J, Ndiaye A, Mane L, Diop M, Ndiaye A, et al. The left gastro epiploic artery: a splenic origin but a variable birth place. Morphologie. 2008;92(296):11-16. Available from: https://doi.org/10.1016/j.morpho.2008.02.004.
8. Jyothi DN, Ramani TV, Saritha S, P G, Rao BS, Anjum A. Cadaveric study of variations in branching pattern of splenic artery. Int J Anat Res. 2015;3(4):162-162. Available from: http://dx.doi.org/10.16965/ijar.2015.284.

9. Bokan RR, , Shyamkishore K, Gawande PA, and. Variations in the origin of the splenic artery and its clinical implications. Med Pulse. 2017;3(1):15-18. Available from: https://dx.doi.org/10. 26611/1001315.

10. Shoumara S, Emura S, Utsumi S, Chen H, Hayakawa D, Yamahira T. Anatomical study of the branches of the celiac trunk. Comparison of the findings with Adachi's classification. Kaibogaku Zasshi. 1991;66:452-461.

11. Oh E, Gross BH, Williams DM. Independent Origin of the Hepatic and Splenic Arteries from the Abdominal Aorta: CT Demonstration. J Comput Assist Tomogr. 1998;22(4):669670. Available from: https://dx.doi.org/10.1097/00004728199807000-00030.

Copyright: (C) the author(s), 2020. It is an open-access article distributed under the terms of the Creative Commons Attribution License (CC BY 4.0), which permits authors to retain ownership of the copyright for their content, and allow anyone to download, reuse, reprint, modify, distribute and/or copy the content as long as the original authors and source are cited.

How to cite this article: Sadeesh T, Prabavathy G. Variation in Branching Pattern of Splenic Artery- A Cadaveric Study. Acad. Anat. Int. 2020;6(2):53-55.

DOI: dx.doi.org/10.21276/aanat.2020.6.2.11

Source of Support: Nil, Conflict of Interest: None declared. 